УДК: 316

\title{
НЕКОТОРЫЕ АСПЕКТЫ ПРОСТРАНСТВЕННОГО РАЗВИТИЯ ТЕРРИТОРИЙ
}

\author{
Насибуллин Рустем Равилевич \\ Кандидат социологических наук, доцент \\ Консультант Национального агентства финансовых исследований
}

\begin{abstract}
Аннотация: В статье раскрываются актуальные аспекты социальнопространственного развития территорий в контексте концептуальной, аналитической и оперативной основы для понимания и решения сложных проблем, возникающих в условиях глобализации.

Существующие очевидные вопросы, возникающие в процессе глобализации социокультурных и экономических процессов, требуют реализации комплексных мер к развитию территорий и усилению мер по обеспечению экономической безопасности наиболее экономически неразвитых регионов. Очевидная дифференциация различных территорий по уровню социального развития способна дестабилизировать основы безопасности жизни социально-территориальной общности людей, что диктует необходимость принятия и реализации эффективных мер по выравниванию существующих диспропорций.
\end{abstract}

Ключевые слова: социально-пространственное развитие территорий, глобализация социокультурных процессов, общество, пространство, планирование, территория.

\section{SOME ASPECTS OF SPATIAL DEVELOPMENT OF TERRITORIES}

\section{Rustem Ravilevich Nasibullin}

Abstract: The article reveals the actual aspects of the socio-spatial development of territories in the context of a conceptual, analytical and operational framework for understanding and solving complex problems arising in the context of globalization.

The existing obvious issues arising in the process of globalization of sociocultural and economic processes require the implementation of comprehensive 


\section{ПЕРЕДОВОЕ РАЗВИТИЕ СОВРЕМЕННОЙ НАУКИ КАК ДРАЙВЕР РОСТА ЭКОНОМИКИ И СОЦИАЛЬНОЙ СФЕРЫ}

measures for the development of territories and strengthening measures to ensure the economic security of the most economically undeveloped regions. The obvious differentiation of different territories according to the level of social development is capable of destabilizing the foundations of the safety of life of the socio-territorial community of people, which dictates the need for the adoption and implementation of effective

Key words: socio-spatial development of territories, globalization of sociocultural processes, society, space, planning, territory.measures to level the existing disproportions.

Понятие пространства - одно из наиболее фундаментальных в теории и практике управления процессом развития территорий. Его осознание органически присуще нам, во-первых, в единстве с категорией времени, как хронотоп, пространственно-временной отрезок, во-вторых, как охватывающая и включающая людей реальность. Не общество существует в пространстве и времени, а пространственно-временное бытие есть форма существования социума.[1]. Основоположником социологии пространства называют немецкого философа и социолога Г. Зиммеля, который и ввел понятие «социальное пространство» в социологическую науку, опубликовав в работе «Социология пространства» (1903)[2].

Вопросы пространственного развития территорий изучаются многими отечественными и зарубежными учеными. В контексте обеспечения конкурентных преимуществ рассматривали Колесник Е. А., Пряхина Г. Н., Колмаковой И. Д., Максимова В. П. [3], Даванкова А. Ю., Замятина Д. Н. [4], Татаркина А. И. [5], Силинцева В. С., Колмаковой Е. М., Гарипова Р. И. [6] и др. Исследования территориального развития и территориальной целостности содержится в работах Колмаковой Е. М. [7], Дикова Я. А., Нусратуллина И. В. [8], Климова Д. В. [9]. Городским агломерациям уделено внимание в работах ученых: Анимицы Е. Г., Гранберга А. Г., Сирина Д. А. [10], Яроцкой Е. В. [11], Кормаковой С. В., Мокичева С. В. [12] и других; а также зарубежных ученых: J. Parr [13], D. Puga [14], Q. Yuan, X. Luo [15], J. TrullénThomas, R. BoixDomenech [16], M. Gerritse, D. Arribas-Bel [17] и др.

Собственно, влияние фактора пространства на региональное развитие рассматривалось еще в первой половине XIX в. сначала в статических, а затем, в начале XX столетия, в динамических теориях размещения. Наиболее известные научные школы сложились в Германии, Швеции, 


\section{ПЕРЕДОВОЕ РАЗВИТИЕ СОВРЕМЕННОЙ НАУКИ КАК ДРАЙВЕР РОСТА ЭКОНОМИКИ И СОЦИАЛЬНОЙ СФЕРЫ}

Великобритании, США и Франции. В Германии были разработаны первые теории размещения (И. фон Тюнен, В. Лаунхардт, А. Вебер, А. Предель, А. Леш, Р. Гроц и другие.) и регулирования территориального развития (В. Кристаллер и А. Леш).[18]

Планирование является сложным и спорным как в теоретическом, так и практическом смыслах, но зачастую относится к типу и этапу управления, который связан с моделями экономики и землепользования, отражающими человеческие ценности и скрытые слои сложной социальной системы общества. Обсуждения обеспечения развития на плановой основе продолжаются и по сегодняшний день. Так, в сборнике «Экономика России. Оксфордский сборник» $[19 ; 20]$ в качестве примера плановой хозяйственной системы предлагают рассмотреть экономическое устройство Советского Союза. Давая определение сложившейся системе хозяйствования в советский период, ее характеризуют как административно-командную, централизованную и государственную экономику. К.Р. Макконнелл и С. Л. Брю характеризуют плановую экономику как систему, основанную на государственной собственности с авторитарным централизованным планированием. Выделяя особенности данной модели, можно отметить, что ее характеризуют фиксированные цены, достижение необходимых показателей с использованием плановых директив. Из недостатков авторы отмечают проблемы координации и стимулирования экономических субъектов. Аналогичной точки зрения придерживаются авторы оксфордского сборника.[21]

В последние десятилетия, пока Россия искала свой особый путь своего развития, подход пространственного развития территорий распространялся, получая все большее признание как инструмент улучшения результатов развития.

Многосторонние подходы, реализованные в пространственной плоскости появляются как более концептуальные, аналитические и оперативные основы для понимания и решения сложных проблем, структурной экономической, социальной и пространственной трансформации, происходящие в глобализационных процессах и быстро меняющихся условиях жизни.

Насколько однородно экономическое пространство можно судить по наличию диспропорций. В числе наиболее значимых:

- дифференциация регионов по уровню социального и экономического развития; 


\section{ПЕРЕДОВОЕ РАЗВИТИЕ СОВРЕМЕННОЙ НАУКИ КАК ДРАЙВЕР РОСТА ЭКОНОМИКИ И СОЦИАЛЬНОЙ СФЕРЫ}

- межрегиональная дифференциация по показателям уровня жизни населения и по уровню его доходов;

- диспропорция между общеэкономическим ростом и развитием инженерной инфраструктуры в центрах концентрации экономической мощи;

- усиливающаяся концентрация населения в Центральном и Южном федеральных округах при прогрессирующей депопуляции в ряде российских регионов, особенно северных;

- внутрирегиональные социально-экономические различия. [22]

Подходы территориального развития являются жизнеспособным вариантом решения проблемы комплексного характера системы управления. Они могут дополнять, улучшать межотраслевую эффективность, влиять на повышение координации и способствовать движению к осуществлению планирования в области развития на будущее. В то же время, неграмотная и «слепая» политика пространственного развития может усугубить существующие проблемы, так как они, как правило, оставляют без внимания те показатели, которые требуют наибольшей поддержки для достижения результата.

Вместе с тем, переход российского государства к инновационному социально ориентированному типу экономического развития требует реализации новой модели социально-пространственного развития и управления российской экономикой, которая позволит, с одной стороны, создавать каркас региональных (республиканских, областных, краевых, окружных) и территориальных (городских, районных) центров сосредоточения экономического роста, способных формировать и передавать сопредельным субъектам инновационные импульсы развития экономики и других сфер жизнедеятельности; с другой стороны,- управлять этими процессами с использованием рыночных институтов и механизмов, выводя на траекторию ускоренного развития окраинные регионы и территории [23].

Сильная поляризация пространства и контраст в направлениях и степени социально-экономического развития его частей приводят к формированию центров и периферии. Для социального пространства России характерным становится нарастание уровня дифференциации развития локальных территорий. Об этом можно судить по динамике основных социальноэкономических показателей их развития.[24]

С точки зрения социально-поселенческого подхода, происходят принципиальные изменения в структуре поселенческой сети, что приводит к 


\section{ПЕРЕДОВОЕ РАЗВИТИЕ СОВРЕМЕННОЙ НАУКИ КАК ДРАЙВЕР РОСТА ЭКОНОМИКИ И СОЦИАЛЬНОЙ СФЕРЫ}

противоречивым изменениям в социальном положении жителей этих поселений. Семьи, переселяющиеся в поселения с развитой социальноэкономической инфраструктурой, одним фактом своего переселения меняют свою жизнь в положительную сторону. У тех семей, которые остаются в малых поселениях с разлагающейся экономической и социальной инфраструктурой, положение будет в дальнейшем еще сильнее ухудшаться. А постоянное ощущение этого развала и безысходности будет способствовать к росту чувства неудовлетворенности уровнем и качеством жизни, что является объективным основанием ухудшения состояния здоровья. Например, по результатам переписи 2010 года в Республике Башкортостан числилось 4532 сельских населенных пункта. Из них 98 населенных пунктов оказалось без жителей, в 321 населенном пункте проживало от одного до 10 человек, число деревень с населением от 11 до 50 человек составило 734. Таким образом в 1153 населенных пунктах, т.е. в 23,7\% деревень из этого числа проживало до 50 человек. А если сюда приплюсовать еще 612 деревень, в которых проживало от 51 до 100 человек, то получится, что в 37,5\% деревнях проживало в сумме 66 705 человек, которые практически были лишены элементарных социальнобытовых достижений цивилизации. Чтобы лучше представить реальный уровень жизни людей, проживающих в таких деревнях, уточним, что если семьи состоят из двух человек, то число домов в таких деревнях около 50. Население в них, если посмотреть с демографических позиций - это преимущественно пожилые женщины, бывшие трудящиеся колхозов, которые практически не в состоянии получить необходимую в этом возрасте регулярную медицинскую помощь, осенне-весенние периоды такие деревни лишены даже постоянного транспортного сообщения и т.д. [25].

В целом, можно смело констатировать то, что процесс принципиальных изменений системы расселения населения продолжается в сторону сокращения количества сельских поселений и роста городского населения. При этом, как подчеркивает Н.В. Зубаревич, «сельская местность депопулирует: 13\% сельских населенных пунктов не имеют постоянного населения, в 24\% живет до 10 человек. В селах с населением менее 300 человек население продолжает сокращаться, и только в селах с населением выше 3000 - растет» [26].

Однако было бы не совсем корректно представить этот процесс в виде линейных изменений. Потеря своих территориальных позиций, в связи с изменением административных границ между городом и деревней, естественно отражается на уровне социокультурного и экономического развития 


\section{ПЕРЕДОВОЕ РАЗВИТИЕ СОВРЕМЕННОЙ НАУКИ КАК ДРАЙВЕР РОСТА ЭКОНОМИКИ И СОЦИАЛЬНОЙ СФЕРЫ}

территории, и, как следствие, на людях, товарах, услугах и информационных системах. Этот процесс не может осуществляться в независимости от города. Напротив, урбанизация - это процесс, связанный с развитием и изменением сельских территорий, под влиянием процессов, происходящих в городе. Например, число деревень с населением менее 10 человек, по данным Всесоюзной переписи 1926 года, составляло на территории Башкортостана 1579, которое к 1979 году сократилось в 9,4 раза и составило 168. Однако к Всероссийской переписи 2010 года их число увеличилось почти в два раза и составило $319[25]$.

С другой стороны, городские районы также претерпевают изменения. Городские, и в частности пригородные районы эволюционируют, в связи с быстрым повышением мобильности и новыми динамическими процессами, относительно направлений городов, а также взаимодействуют между собой.

В целом влияние города на окружающую территорию зависит от его размера и местоположения. Чем крупнее город и чем в менее плотной социально-экономической среде он расположен, тем большую зону повышенной плотности сельского населения он формирует. Таким образом, города поглощают население обширных сельских территорий, одновременно создавая вокруг себя мощные поля влияния на сельскую местность, способствуя концентрации в пригородных зонах сельскохозяйственного производства, направленного на удовлетворение собственных нужд. Поэтому там, где выше плотность городов и где они крупнее, шире ареалы относительного благополучия сельского хозяйства, а значит, и населения. При этом все более усиливается разрыв по уровню развития между городами и сельскими территориями [27].

Столкнувшись с неустойчивостью исторической модели развития современным тенденциям, города сталкиваются с огромными проблемами: быстрый рост количества жителей, отсутствие или увеличение издержек для доступа к основным услугам и здоровому питанию, загрязнение окружающей среды, негативные последствия, связанные с изменением климата, отсутствие продуктивных возможностей трудоустройства и т. д.

Bсе эти вопросы ограничивают перспективы достойной жизни и могут подпитывать социальные беспорядки. Более того, большинство из этих проблем непропорционально присутствуют в малом и среднем бизнесе.

Сегодня актуальность вопроса развития и территориального планирования сельских и городских территорий, которые всегда управлялись и 


\section{ПЕРЕДОВОЕ РАЗВИТИЕ СОВРЕМЕННОЙ НАУКИ КАК ДРАЙВЕР РОСТА ЭКОНОМИКИ И СОЦИАЛЬНОЙ СФЕРЫ}

регулировались государственной политикой, подвергается вызовам. Эта классификация территорий все еще актуальна для понимания многообразия социально-экономических и политических свойств сельских и городских сообществ, в то время как пространственно-сегментированные интервенции усиливают пространственные разрывы и предотвращают адекватные ответы на потребности развития, такие как инфраструктура, услуги и общее обеспечение населения товарами. Необходимость изменения политики развития территориальной и социально-пространственной системы управления очевидно назрела. Большинство ответов, в том числе, вытекает из переосмысления и укрепления связи между городом и деревней.

Таким образом, для разработки политики развития, адаптированной к новым территориальным реалиям, необходимо учитывать весь набор пространственной динамики, которая охарактеризует территорию. Он может включать в себя, например, различные роли малых городов и поселков и более отдаленные сельские регионы, различные сети поддержки потока людей, физические товары и информацию о нахождении их в упомянутом пространстве. В данный набор также должны быть включены властные отношения на различных административных уровнях и потенциальные конфликты интересов среди многочисленных заинтересованных сторон в каждой конкретной области.

Понимание этих новых динамических процессов имеет первостепенное значение для восстановления развития системы. Пространственноадаптированное мероприятие подразумевает расположение людей на своих местах по месту жительства, как центра прилагающего усилие по развитию. Они являются ключевыми для эффективной политики. Следовательно, требуется обновление и диверсификация аналитических рамок и методологических справочных материалов, инструментов и индикаторов для использования в работе.

В перспективе можно рассматривать территорию как пространство управления человеческой деятельностью, где будущие проекты задумываются и, соответственно реализовываются. Управляемая территория может находиться под влиянием сообщества субъектов, имеющих дело с общими вызовами по раздельным действиям. Она включает в себя все экологические, социальные, политические, культурные и экономические активы и процессы, взаимодействующие внутри него. 


\section{ПЕРЕДОВОЕ РАЗВИТИЕ СОВРЕМЕННОЙ НАУКИ КАК ДРАЙВЕР РОСТА ЭКОНОМИКИ И СОЦИАЛЬНОЙ СФЕРЫ}

Основные «якоря» перспективы стратегии территориального развития это, к примеру, территориальные активы и взаимозависимость между различными местами, включая связи между городом и деревней, что может позволить интегрировать отраслевую политику в соответствующих масштабах деятельности территории.

Не сводя подход пространственного развития территорий к локальному уровню, территориальная перспектива учитывает несколько уровней пространственной организации, как например, в местном, региональном, и международных масштабах с учетом последствий и воздействий глобализации. Для этого потребуется смена парадигмы управления государством. Сельские и городские пространства и отдельные органы власти должны быть разъединены, чтобы деятельность была основана на многостороннем участии в механизме управления и принятии решений на уровне всей страны.

Территориальная перспектива развития в дальнейшем позволяет выявить синергетические связи между различными секторами. Но, система многосекторного развития не должна отменять отраслевые политические решения, а скорее дополнять и укреплять их с целью обеспечения наивысших результатов в социальной, экономической и других сферах.

На государственном уровне территориальная перспектива - это больше, чем просто координация государственной политики. Чтобы лучше определить и сформулировать цели отраслевой политики, она должна опираться на диагностику и анализ потенциальных возможностей и адекватных ограничений исходя из масштаба и в то же время, признавая приоритеты, потенциал и возможности в долгосрочной перспективе для сохранения, восстановления и улучшения природного, физического и человеческого капитала. Соответственно, некоторая ответственность за планирование, финансирование и управление может быть передана местным участникам и законным местным властям.

Не нужно путать территориальные подходы с подходами, применяемыми в комплексных проектах развития сельских районов, которые появились в 1970е годы и были часто управляемы экспертами, как способ повышения эффективности развития сельских районов в данной местности. Они включали широкий диапазон секторальной интервенции, и, как правило, создавали параллельные структуры в сельских районах, без учета специфики сельских и городские взаимосвязей, и отсутствия действий, реально отражающихся на конкретном географическом пространстве. Наоборот, территориальный подход 


\section{ПЕРЕДОВОЕ РАЗВИТИЕ СОВРЕМЕННОЙ НАУКИ КАК ДРАЙВЕР РОСТА ЭКОНОМИКИ И СОЦИАЛЬНОЙ СФЕРЫ}

не ограничивается локальным уровнем развития. Он подразумевает больше, чем административная децентрализация и включает в себя программный аспект и процессы принятия решений.

Подход пространственного развития территорий также может применяться и за пределами биофизических подходов, охватывая интегрированное ландшафтное управление, которое учитывает социальноэкологические параметры взаимодействия между видами экосистемы, а также социально-экономические аспекты использования природных ресурсов. Более того, учитывается, что населенные пункты различных размеров являются встроенными в более широкий ландшафт и взаимную динамику между этими пространствами. Так же при территориальном подходе принимается пространственная перспектива развития, не ограничивающаяся ранее существовавшими административными границами и имеющая возможность определения соответствующих функциональных территорий, которые имеют смысл реагирования на коллективно выявленные проблемы развития для местных субъектов.

Какова бы ни была политика развития, программа или проект, подход территориального развития является инструментальным в улучшении конструкции, внедрении, мониторинге и оценки государственных и частных инициатив.

Что касается самого процесса, следующие общие шаги являются необходимыми:

- Предварительный диагноз, основанный на обзоре политической сферы и на основе имеющихся данных анализ социально-экономических показателей и информирование территориальных структур.

- Консультации и работа с участием многих заинтересованных сторон.

- Регулярные исследования и обмен знаниями для понимания территориальной динамики, анализ показателей прошлого и обсуждение сценария вероятного развития событий, основанного на территориальном прогнозировании.

- Идентификация главных сил для перемен, определение сильных и слабых сторон, и расстановка приоритетов для действий.

- Предварительное проектирование проектов или программ и определение поддержки, необходимой для их реализации. 


\section{ПЕРЕДОВОЕ РАЗВИТИЕ СОВРЕМЕННОЙ НАУКИ КАК ДРАЙВЕР РОСТА ЭКОНОМИКИ И СОЦИАЛЬНОЙ СФЕРЫ}

- Определение специальных структур управления, относящихся к проектам или программам (например, совместное создание платформы для обмена информацией, обратная связь, совместный мониторинг).

- Осуществление территориальных проектов и программ.

- Мониторинг, оценка и перепроектирование этих проектов и программ.

- Поддержка эффективности территориальных подходов и облегчение координации и стратегического планирования на любом из уровней реализации проектов с помощью обеспечения человеческими и финансовым ресурсами.

- Преодоление секторальных взглядов и задействование территориальных потенциалов.

- Укрепление аналитического потенциала и реинвестирование в развитие стратегии на местном и национальном уровнях.

- Укрепление территориальной статистики и информационных систем на различных масштабах, для обеспечения данными для полного и последовательного описания, анализа и мониторинга территориальных долгосрочных социально-экономических планов.

- Упрощение доступа к данным для понимания процессов и доказательства для всех заинтересованных сторон.

Важным фактором успеха является заставить работать территориальные сектора, что является результатом функциональной децентрализации и многоуровневой системой действий.

Децентрализация является неотъемлемой частью пространственного подхода развития территорий, обеспечивающая релевантность, реализацию, мониторинг и оценку мероприятий в области развития. Принятие территориальной перспективы и измерение прогресса в области развития в этих процессах усиливают оба направления принятия стратегических решений и идентификацию эффективных мер воздействия, что помогает определить наборы показателей успешности или не успешности, борьбы с обоими сторонами политики, программ и проектов, и их вклад в территориальное развитие.

- Привлечение партнеров по развитию (правительство, научные круги, гражданское общество общественные организации, региональные организации, частный сектор) для учета территориального подхода в их программах.

- Мобилизация междисциплинарных усилий и исследований, направленных на повышение базы знаний и укрепление теоретического и практического уровня, а также инструментария и методологии построения 


\section{ПЕРЕДОВОЕ РАЗВИТИЕ СОВРЕМЕННОЙ НАУКИ КАК ДРАЙВЕР РОСТА ЭКОНОМИКИ И СОЦИАЛЬНОЙ СФЕРЫ}

теории изменений и поддержки сдвига парадигмы, основанного на положительных результатах.

На фоне всего вышеизложенного, территориальные подходы могут оказывать поддержку идентификации и синергетическому использованию взаимосвязей между усилиями по развитию "единой цели".

Политики могут опираться на информацию, созданную в результате реализации территориальных подходов в целях устранения информационных пробелов, принимать более обоснованные решения в различных секторах. Политики и частный сектор могут использовать территориальную информацию для инвестиций. Децентрализованные системы могут применять территориальный подход к улучшению локализации национальных, региональных или глобальных целей развития.

Широкое участие в инклюзивном измерении изменений, вызванных данной программой, также способствует повышению заинтересованности сторон к коллективному расширению прав и возможностей.

Территориальные подходы способствуют инклюзивному развитию путем поддержки роста во всех регионах, ориентируясь на те территории, в которых экономический рост уже происходит.

«Регионы-чемпионы» должны помочь развитию экономически слабых соседних территорий, что позволит на практике реализовать принцип субсидиарности в региональной политике.[28]

\section{Список литературы}

1. А.Ю. Барковская. Социологическая интерпретация категории «социальное пространство». ISSN 1998-9946. Вестн. Волгогр. гос. ун-та. Сер. 7, Филос. 2013. № 1 (19) с. 49-55

2. Зиммель, Г. Социология пространства / Г. Зиммель // Избранное. В 2 т. Т. 2. Созерцание жизни / Г. Зиммель. - М. : Юристь, 1996. - 607 с. - (Серия «Лики культуры»).

3. Берг Н. А., Колесник Е. А., Колмакова И. Д., Максимов В. П. и др.// Научно-методические основы обеспечения самодостаточности малых городов. - Екатеринбург, 2009.

4. Даванков, А. Ю. Особенности управления пространственным развитием крупнейшего города в современной России - Челябинск, 2008. - 132 c. 


\section{ПЕРЕДОВОЕ РАЗВИТИЕ СОВРЕМЕННОЙ НАУКИ КАК ДРАЙВЕР РОСТА ЭКОНОМИКИ И СОЦИАЛЬНОЙ СФЕРЫ}

5. Татаркин А. И. Конкурентная активность территорий в пространственном развитии Российской Федерации // Экономика и упр. - 2012. - № 11 (85). - С. 20-29.

6. Колмакова И. Д., Колмакова Е. М., Силинцев В. С., Гарипов Р. И. Территориальное планирование сбалансированного социо-экологоэкономического развития // Управление сбалансированным развитием территориальных систем: вопросы теории и практики. - Челябинск, 2016. - С. 250-291.

7. Колмакова Е. М. Потенциал и ограничения реализации пространственно-инвестиционно-инновационной модели роста региона // Вестн. Челяб. гос. ун-та. - 2014. - № 21 (350). Экономика. Вып. 47. - С. 82-86.

8. Диков Я. А. Пространственное развитие территорий: комплексный подход // Экон. исслед. и разработки. - 2017. - № 7. - С. 15-23.

9. Климов Д. В. Экономические инструменты управления пространственным развитием территорий // Terra Economicus. - 2009. - T. 7, № 3-3. - C. 218-220.

10. Сирина Д. А. Эволюция принципов развития Свердловской агломерации в XX-XXI вв. // Науч. обозрение. - 2016. - № 17. - С. 47-55.

11. Яроцкая Е. В. К вопросу о критериях идентификации городской агломерации в условиях инновационного развития регионов // Вестн. науки Сибири. - 2012. - № 5 (6). - С. 185-190.

12. Кормакова Е. С. Агломерации - стратегическая составляющая устойчивого развития региональной экономической системы // Экон. науки. 2011. - № 81. - C. 99-103.

13. Parr J. B. Missing elements in the analysis of agglomeration economies // Intern. Regional Sci. Rev. - 2002. - Vol. 25, iss. 2. - P. 151-168.

14. Puga D. The magnitude and causes of agglomeration economies // J. of Regional Sci. - 2010. - Vol. 50, iss. 1. - P. 203-219.

15. Yuan Q. A comparative study on agglomeration effects of the central cities of three urban agglomerations in China - a case study of producer services // Advances in Intelligent Systems and Computing. 2nd Intern. Conf. on Intelligent and Interactive Systems and Applications, IISA 2017, Beijing, China, 17-18 June 2017. Beijing, 2018. - Vol. 686. - P. 664-668.

16. Trullén-Thomas J. The Marshallian industrial district and inclusive urban growth strategy // Economia e Politica Industriale. - 2017. - Vol. 44, iss. 4. - P. 449456. 
17. Gerritse M. Concrete agglomeration benefits: do roads improve urban connections or just attract more people? // Regional Studies. - 2017.

18. Всемирная энциклопедия: Философия / Глав. науч. ред. и сост. А.А. Грицанов. М.: АСТ, 2001. 1312 с.

19. Эрксон Р. Командная экономика и ее наследие // The Oxford Handbook of the Russian Economy, First Edition. М. : Издательство Института Гайдара, 2015.

20. The Oxford Handbook of the Russian Economy, First Edition. M. : Издательство Института Гайдара, 2015.

21. Федотов В.А.Обеспечение конкурентоспособности в условиях плановой системы хозяйствования. Управленческое консультирование. 2019.№4, -c.154-161

22. Ильин В. А. Методы преодоления пространственной социальноэкономической дифференциации // Федерализм. - 2012. - № 3 (67) - С. 7-18.

23. Татаркин А. Развитие экономического пространства Российской Федерации на основе кластерных принципов // Федерализм. - 2012. - № 1. - С. 45-60.

24. Ускова Т.В. Пространственное развитие территорий: состояние, тенденции, пути снижения рисков // Проблемы развития территории. - №1 (75). -2015 . - C.7-14.

25. Башкортостан в цифрах/Территориальный орган Федеральной службы государственной статистики по Республике Башкортостан.- Уфа: Китап, 2018. C. 86

26. Зубаревич Н. В. Территориальное развитие России: перспективы, проблемы и пути их решения // Практика муниципального управления. - 2012. - № 10. - Режим доступа : http://www.gkh.ru/journals/9131/80123

27. Ускова Т. В. Управление устойчивым развитием региона: монография / Т. В. Ускова. - Вологда: Ин-т социально-экономического развития территорий PAH, 2009. $-355 \mathrm{c}$.

28. Перелыгин Ю., Княгин В. Пространственное развитие России в долгосрочной перспективе // Российское экспертное обозрение. - №1-2. -2007 г. - C. 6-11. 